\title{
Experienced Journeyman Machinist Killed While Operating an Engine Lathe
}

\section{SUMMARY}

A 69-yr-old journeyman machinist with over 30 years of experience was killed while operating an engine lathe. The victim was using the lathe to shape an eccentric shaft. When he reached over the work piece to smooth out a radiused transition with emery cloth and a file in hand his loose clothing (left arm sleeve) became entangled around the rotating work piece near the lathe tailstock. He was pulled into the part and suffered multiple fractures to his left arm and injuries to the neck and chest as he was struck repeatedly by the eccentric shaft. A coworker rushed to his aid and instinctively pushed the red button on the lathe to stop the machine. However, the red button was not an

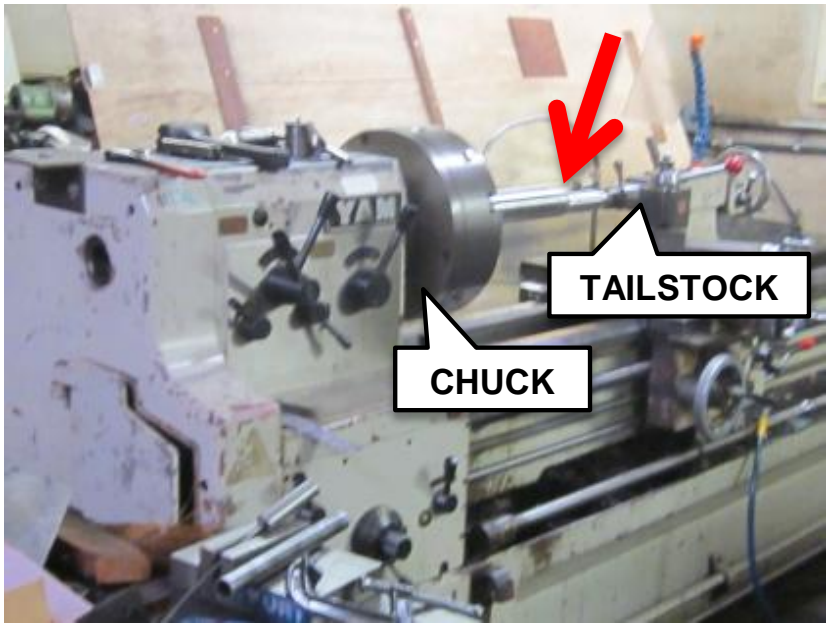

The engine lathe where the event occurred. The arrow indicates where the victim became entangled. emergency stop and the machine continued. The victim was lifeflighted and died enroute to the hospital. The co-worker suffered non-life threatening injuries.

\section{RECOMMENDATIONS}

- Employers should establish, communicate and enforce a clothing policy specific to the work environment and particularly for machine operators.

- Employers should establish formal training on recognized hazards, injury prevention and emergency procedures, and to communicate expectations to adhere to safe practices and policies.

- Supervision should monitor, reinforce safe behaviors, and immediately correct unsafe behaviors or conditions. 
- Job hazard analyses should be conducted by operators and supervisors and should include a review of the manufacturer's equipment/operator's manual, machine labeling, color coding, etc., especially for legacy machines.

- Employers should implement preventive maintenance and inspection processes for hazardous machines. Where necessary, employers should install, adjust, label and/or repair appropriate controls (e.g., machine guards, emergency stops).

OR-FACE supports the prioritization of safety interventions using a hierarchy of safety controls, where top priorities are hazard elimination or substitution, followed by engineering controls, administrative controls (including training and work practices), and personal protective equipment.

\section{INTRODUCTION}

In October 2012, a machinist suffered fatal injuries while operating an engine lathe after he reached over the rotating work piece and was entangled in the machine. OR-FACE was notified of the event by the Oregon Public Health Program and obtained medical examiner and police reports. To complete the report OR-FACE obtained OR-OSHA field and investigation documents including recorded interviews and held follow-up interviews with the OR-OSHA investigator.

The machinist's employer was operating a machine shop where steel stock was machined to make parts. Equipment in the shop included engine lathes, mills, and computer numerically controlled (CNC) lathes. The employer owned other machine shops in Oregon. There were six employees at the location where the incident occurred.

On the day of the incident the machinist was operating an engine lathe turning an eccentric shaft. These shafts have offset centers, as shown in the photograph of a finished product with a schematic drawing of the part face. Because of the offset centers, the surface of one end of the shaft rotates around the lathe centerline during the machining operation. During the OR-OSHA interview with the shop foreman, he indicated that these shafts required the use of emery cloth or file handled by the operator to smooth the transition of the radius of the two centers. Eccentric shafts of varying lengths were produced by the employer for vibratory equipment.

The employer indicated that only experienced machinists were hired and were expected to know safe work practices. There was no formal process to train employees, 
review equipment safety features, or instruct them in the safe operation of machinery, tools, equipment, process, or practice which they were authorized to use or apply. The employer, in a recorded interview, stated that he has operated machine shops for 30+ years and in addition to the two he currently owned this machine shop was purchased four months prior to the incident. At this site, personal protective equipment required and provided by the employer for operating a lathe were safety glasses/goggles and hearing protection. Gloves were provided for handling steel stock. At the other employer sites, clothing was also made available for machine operators.

The victim was a 69-year-old master journeyman machinist with greater than 30 years of experience. The shop foreman stated that the victim had been hired weeks prior to the incident.

\section{INVESTIGATION}

The shop where the incident occurred had different models of engine lathes with different safety features. The engine lathe involved in the incident was manufactured in Taiwan and believed to have been manufactured 40 years ago. Another shop lathe was manufactured in England in 1996. The safety features for the recognized lathe hazards (e.g., rotating chuck) were different. For example, an interlocking chuck guard was a component of the newer lathe while there was no chuck guard for the older lathe. In addition, whereas the red button on the newer lathe was an emergency stop, it was not on the older lathe. The manual indicated it was an "inch" (could be a translation of jog) button. Pushing and holding this button in causes the lathe to rotate. Releasing the button stops the lathe. This control is used for checking tool set-ups before machining the work piece. Multiple employees thought the red "inch" button on the engine lathe was an emergency stop. Quickly stopping this machine was accomplished by stepping on a foot-operated brake bar, located just above floor level and extending along the front of the machine.

On the day of the incident, the machinist was turning his first short length eccentric shaft (work piece). In a recorded interview the foreman informed the OR-OSHA investigator that the victim had completed three or four longer eccentric shafts previous to the incident and the hazards were similar. The short shaft dimensions were: 30 1/2 inches in total length with diameters of $15 / 8$ and 3 inches. The machinist had completed "rough machining" the work piece which had

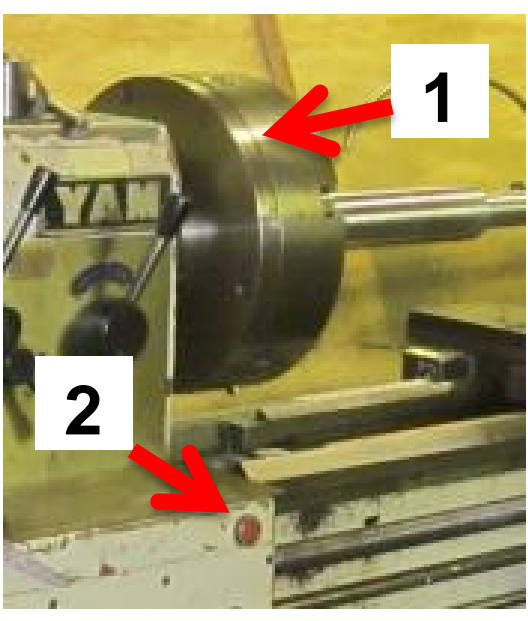

ABOVE: (1) Lathe involved in the incident with unguarded chuck and (2) red "inch" (or jog) button.

BELOW: (3) Lathe manufactured in England also on site with interlocking chuck guard and (4) red "emergency stop."

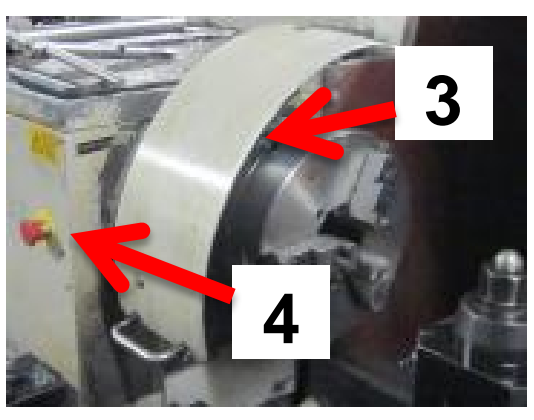
taken him approximately seven hours. For the same part, the foreman mentioned that it typically took him approximately 3-4 hours to complete the job. Since this was the machinist's first short length eccentric shaft he told the machinist to take his time. Approximately 45 minutes before the incident, the machinist told the shop foreman that the part he was working on had slipped in 
the chuck jaws, and that this had damaged the work piece at the chucked end. The foreman instructed him to finish the part by first smoothing the radii transition at the end near the tailstock opposite the chuck end, and then afterward reverse the part with the damaged end positioned on the lathe tailstock to fix it. The foreman stated that smoothing could only be done by placing an emery cloth or file (not both) in hand and carefully applying light pressure as the part turned on the lathe.

While demonstrating turning the same part on the newer lathe, the foreman mentioned that the newer lathe generated the transition required on the work piece, therefore, did not require as much time to manually smooth the transition. Evidence indicates that the machinist may have used emery cloth wrapped around a rat tail file at the time of the incident. Remnants of emery cloth approximately 12 inches long and a rat tail file were found in proximity to the lathe. The emery cloth appeared to have been coiled around an object with a diameter the size of the rat tail file.

When examining the work piece that the machinist had been turning, the shop foreman stated that the rough surface could grab clothing or gloves. He also indicated that he would have set the spindle speed to no more than $330 \mathrm{rpm}$. The settings on the lathe indicated a spindle speed of approximately $590 \mathrm{rpm}$ when the incident occurred. This speed may have caused machine vibration and greater air turbulence similar to a fan intake increasing the potential for entanglement with loose clothing.

The co-workers described the machinist's typical clothing as layered and that they were not aware of a company clothing policy but it was understood that loose clothing was a known hazard. On the day of the incident the machinist wore a long-sleeved thermal shirt underneath a sweatshirt with sleeves cut just above the elbow. After reviewing the scene, the OR-OSHA investigator believed that the loose fitting cut-off sweatshirt was the victim's first point of entanglement with the rotating part. Although co-workers indicated that they had not previously observed the victim wearing gloves while operating a lathe, evidence collected revealed that he wore gloves at the time of the incident. Whether the gloves played a role in the entanglement is uncertain but remnants of the gloves were found within the lathe. He may have donned the gloves to reverse the part but after the conversation with the supervisor, he may have decided to smooth the transition on the undamaged end before reversing the part and did not remove his gloves. Safety glasses, side shields and hearing protection were provided and required by the employer. Other personal protective equipment was task specific. The machinist's glasses were found at the lathe and co-workers stated that he had been previously observed with safety goggles over his prescription glasses.

The witness, a less-experienced machinist, who had been operating a CNC lathe approximately 30 feet from the engine lathe, reported that he had observed the victim position his body 90 degrees or sideways to the lathe and held a file and/or emery cloth in his left hand over the rotating part while leaning toward the lathe. A strange "winding-up" sound caused the witness to look towards the sound where he saw the victim's left arm wound around the part pulling his body into the rotating shaft. The witness rushed to the scene and instinctively and repeatedly pushed what he believed to be a red emergency stop button. However, the lathe continued to operate while the witness tried to hold the victim's chest and head away from the rotating part. 
While doing so his own arm was repeatedly struck by the eccentric shaft until his cry for help summoned the manager who upon arriving at the scene immediately stepped on the brake bar, stopping the machine.

Co-workers untangled the victim as emergency medical service (EMS) arrived. Medics performed lifesaving procedures. When a heartbeat was detected, he was immediately transported by Life Flight to a hospital. While in transit cardiopulmonary resuscitation (CPR) was re-started. He arrived at the hospital with no signs of life and pronounced dead.

\section{CAUSE OF DEATH: Lacerating and penetrating injuries of neck and chest}

\section{RECOMMENDATIONS/DISCUSSION}

Recommendation \#1: Employers should establish, communicate and enforce a clothing policy specific to the work environment and particularly for machine operators.

- The OR-OSHA investigator believed that the victim's loose fitting cut-off sweatshirt was the first point of entanglement with the work piece. The most common causes of death and injury from metal lathes include entanglement of clothing in moving parts, being hit by loose objects on the lathe (e.g., chuck keys, tools, metal shavings) and being struck by a part that has not been adequately secured (see reference Work Safe Victoria, September 2010). To prevent entanglement, recognized accepted practices include prohibiting loose clothing, jewelry, gloves and unsecured long hair around rotating equipment.

- Management should consider providing uniform clothing for machine operators appropriate for the tasks. The employer did provide clothing for machine operators at the other sites but did not require their use. Uniform clothing would reduce the risk of loose clothing entanglement with rotating machinery/parts and ensure adherence to a clothing policy. Moreover, this common practice would reduce the need to continuously assess appropriate employee attire around hazardous machinery.

Recommendation \#2: Employers should establish formal training on recognized hazards, injury prevention and emergency procedures, and to communicate expectations to adhere to safe practices and policies.

- Although an experienced machine operator is likely to know the hazards of most machines they work with, it is the employers' responsibility to ensure that all employees are trained to recognize and prevent exposure to known hazards in their work environment. While the victim in the current incident was a highly experienced machine operator, it is possible (but not known) that he had limited experience with the particular type of eccentric shaft. According to the foreman, the victim had been working on the part for seven hours whereas he, the foreman, typically took 3-4 hours and at a slower spindle speed to complete the task. This may have been an indication of lack of experience with the work piece or nuances with that particular engine lathe and also that the victim may have been unaware of the how the foreman conducted the same task. Formal training and review is particularly important with new employees of all 
experience levels to communicate expectations that all will follow best safety practices and to empower employees to report unsafe conditions.

- Initial and periodic training should include safe operating procedures (SOPs). Using an emery cloth to deburr, polish, or size parts while they are rotating in lathes can place the operator at high risk of entanglement. SOPs developed from a job hazard analysis (see OSHA, Job Hazard Analysis, 2002) conducted by operator and supervision may have identified other means to accomplish the job without the risk of entanglement, for example the use of a tool post or the practices described in the Health and Safety Executive (November 2004) reference, e.g., backing board, nutcracker. Additionally, other equipment/tools such as a flap wheel and buffing wheel mounted on a stationary grinder that would reduce the risk of entanglement to accomplish the task could have been considered. However, if no other means was practicable then proper emery cloth use should be clearly specified in the SOPs and enforced. In this case the SOP could have included a pre-job clothing assessment, target spindle speed, etc.

- Training should include emergency procedures for possible incidents with each type of machine in the workplace. Supervisors should review the safety features of hazardous machinery with all employees who are exposed to the hazards to maximize effective and safe emergency response. The co-worker who tried to aid the victim did not know how to stop the machine, suffered injuries while trying to rescue the victim, and could have become entangled himself.

\section{Recommendation \#3: Supervision should monitor, reinforce safe behaviors, and immediately correct unsafe behaviors or conditions.}

- Supervisors must monitor and reinforce employees' behavior when they are performing work tasks. When at-risk practices are observed that place employees in immediate danger, supervisors should immediately correct those practices or hazardous condition. The victim was observed with loose clothing, but no corrective action was taken. In addition, evidence suggests that contrary to the foreman's common practice, the spindle speed was set too fast and that both the emery cloth and file were used together at the same time.

- Supervisors should model safe work practices, such as type of clothing worn to work, and ask employees to make adjustments. A monitoring supervisor can also remind or redirect employees to take appropriate precautions. For example, a supervisor who recognized that an employee was wearing loose fitting clothing could ask them to change, especially before performing work over a rotating part. Also, the victim may have put on gloves in preparation to reverse the part and fix the damaged end, but then simply forgot to remove them when he was asked to finish his task before reversing the part. The victim's eagerness to complete the task and concern about the damaged end of the part may have contributed to leaving his gloves on, or working with excessive spindle speed. A monitoring supervisor can help reduce the risk of skipped steps or poor practices. 
Recommendation \#4: Job hazard analyses should be conducted by operators and supervisors and should include a review of the manufacturer's equipment/operator's manual, machine labeling, color coding, etc., especially for legacy machines.

- Job hazard analysis is especially critical when there are legacy machines with varying hazard controls. These job hazard analyses should be used to create SOPs that would eliminate and/or control the hazards. The investigation revealed that there were several engine lathes in the shop. The engineering or regulatory standards at the time of manufacture or country where manufactured were likely different. For example, the machine involved in the incident had a red button that was not an emergency stop whereas another engine lathe had two red emergency stops. Current OSHA regulations or ANSI Z535.1-1998 do not specify which machine parts require color-coding. However, a standard interpretation (see reference OSHA, Standards Interpretation) states, that the "employer has the responsibility to evaluate the machine and determine if any portion needs to be color-coded." In this particular case employees assumed that the red button on the engine lathe was an emergency stop. Training, labeling, or changing the color of the button after a job hazard analysis would have corrected the mistaken assumption that the "inch" button was an emergency stop. After the incident the employer painted the brake bar red, covered the "inch button" and had begun the process to add an emergency stop on the lathe involved in the incident.

- Job hazard analysis is one of several methods to engage employees in the safety process. Involving workers will bring their "unique insights and energy in achieving goals and objectives," of a safety program (OSHA Small Business Handbook) and empower them to address safety concerns. "Engage everyone" is one of the 10 keys to success for injury prevention (National

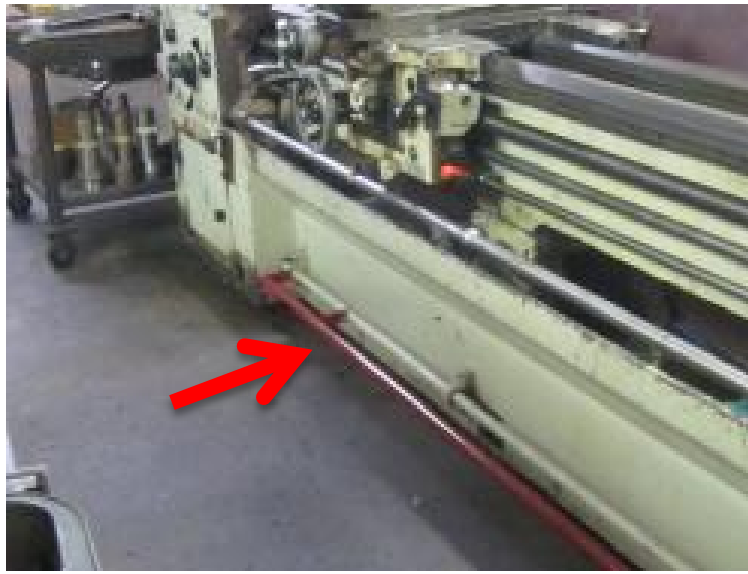

Brake bar on the engine lathe, which was painted red following the incident Institute for Occupational Safety and Health, "Safety and Work: the keys to success in small enterprises).

Recommendation \#5: Employers should implement preventive maintenance and inspection processes for hazardous machines. Where necessary, employers should install, adjust, label and/or repair appropriate controls (e.g., machine guards, emergency stops).

- During routine preventive maintenance it might have been discovered that the red button was not an emergency stop. Preventive maintenance can also ensure controls for recognized hazards are installed consistently across similar equipment. Manufacturers of equipment and aftermarket safety equipment should be consulted for the type of controls. 
- Periodic inspections or work practice observations by designated employees, such as a safety committee, might have identified and reported unsafe conditions and deviations from safe practices, e.g., spindle speed, loose clothing, damaged tools, and uncontrolled hazards. The damaged chuck wrench next to the engine lathe (twisted core shank) required excessive force to ensure that the part was adequately gripped by the chuck jaws. Inadequate grip likely caused the part to slip resulting in damage of the part towards the chuck end. Furthermore, a loose inadequately gripped part on a lathe is a serious additional hazard to operators or persons nearby (Oregon OSHA, Hazard Alert 2993). There is no evidence that the part came loose in the current incident, but a process in place to identify and report damaged tools or malfunctioning equipment might have prevented damage to the part. The damage may not have contributed to the incident but it may have been a distraction leading to risky behaviors. As with job hazard analyses, employee participation in inspections and observations will further employee engagement and enhance the injury and illness prevention processes.

\section{REFERENCES}

Health and Safety Executive (November 2004). SE Engineering Information Sheet No. 2, "Accidents at metalworking lathes using emery cloth." Available online: http://www.hse.gov.uk/pubns/eis2.pdf

National Institute for Occupational Safety and Health, "Safety and Work: the keys to success in small enterprises.” Available online:

http://safety-work.org/en/pages/home/10_keys_to_success.html

Occupational Safety \& Health Administration, Job Hazard Analysis 2002 (Revised)

Available online: https://www.osha.gov/Publications/osha3071.pdf

Occupational Safety \& Health Administration (OSHA), Small Business Handbook Small Business Safety and Health Management Series, OSHA 2209-02R 2005. Available online: https://www.osha.gov/Publications/smallbusiness/small-business.html\#mancom

Occupational Safety \& Health Administration (OSHA), Standards Interpretation. Available online:

https://www.osha.gov/pls/oshaweb/owadisp.show_document?p_table=INTERPRETATION $\underline{\text { S\&p_id }=24636}$

Oregon OSHA, Hazard Alert 2993 “Lathe Operation Safety” (R42/2008). Available online: http://www.orosha.org/pdf/hazards/2993-15.pdf

Oregon OSHA (2008) Oregon Administrative Rules, Chapter 437, Division 2 General Occupational Safety \& Health Rules, Subdivision J, General Environmental Controls. Available online: http://www.orosha.org/pdf/rules/division_2/1910-144.pdf 
Oregon OSHA (2009). Oregon Administrative Rules, Chapter 437, Division 2 General Occupational Safety \& Health Rules, Subdivision O, "Machinery and Machine Guarding." Available online: http://www.orosha.org/pdf/rules/division_2/div2_o.pdf\#page=23

Oregon OSHA, 440-2980 (9/10), Machine Safeguarding at the Point of Operation. Available online: http://www.orosha.org/pdf/pubs/2980.pdf

Oregon OSHA Program Directive A-236 "Guarding: Metal Lathe Chucks (Engine Lathes)” (April 4, 2000). Available Online: http://orosha.org/pdf/pds/pd-236.pdf

Safety + Health (July 1, 2012). Lathe protection device. Available online: http://www.safetyandhealthmagazine.com/articles/7507

Work Safe Victoria (September 2010). Guidance Note, Safe use of metal turning lathes. Available online: http://www.worksafe.vic.gov.au/_ data/assets/pdf_file/0016/12148/GN2BTurning2BLathes _web.pdf

\section{FOR MORE INFORMATION}

OR-FACE/Oregon Institute of Occupational Health Sciences L606

Oregon Health \& Science University

3181 SW Sam Jackson Park Rd

Portland OR 97239-3098

Phone 503-494-2281

Email: orface@ohsu.edu

Website: www.ohsu.edu/croet/face/

Oregon Fatality Assessment and Control Evaluation (OR-FACE) is a project of the Oregon Institute of Occupational Health Sciences at Oregon Health \& Science University (OHSU). OR-FACE is supported by a cooperative agreement with the National Institute for Occupational Safety and Health (NIOSH) (grant \#2U60OH008472) through the Occupational Public Health Program (OPHP) of the Public Health Division of the Oregon Health Authority.

OR-FACE reports are for information, research, or occupational injury control only. Safety and health practices may have changed since the investigation was conducted and the report was completed. Persons needing regulatory compliance information should consult the appropriate regulatory agency.

This report is the product of our Cooperative State partner and is presented here in its original unedited form from the state. The findings and conclusions in each report are those of the individual Cooperative State partner and do not necessarily reflect the views or policy of the National Institute for Occupational Safety and Health. 